\title{
Perda de amostras em tissue microarray: comparação entre técnicas com uso de fita adesiva comercial, lâminas silanizadas pelo método tradicional ou por método modificado
}

\author{
Loss of tissue samples in the tissue microarray: comparison between techniques using commercial adhesive \\ tape, silane-coated microslides by the conventional method and by a modified technique
}

Joaquim Soares de Almeida ${ }^{1}$; Henrique de Oliveira Costa ${ }^{2}$; Flavio de Oliveira Lima²; Nathanael Pinheiro Jr. ${ }^{3}$; Celina Tizuko Fujiyama Oshima ${ }^{4}$; Thiago Simão Gomes ${ }^{5}$; Marcello Franco ${ }^{6}$

\section{unitermos resumo}

TMA

Perda de amostras

Imuno-histoquímica

Lâminas silanizadas
Introdução/objetivo: O microarranjo tecidual, ou tissue microarray (TMA), permite avaliar múltiplas amostras de tecido em um único bloco. Um dos problemas do TMA é o descolamento dos cortes teciduais, por isso, para reduzir essa perda, tem-se utilizado fita adesiva especial comercial. Não há relatos comparando o uso dessas fitas adesivas com a técnica de silanização modificada. O objetivo desse estudo foi comparar as perdas de cortes entre lâminas usando fitas adesivas comerciais, lâminas silanizadas por técnica convencional e lâminas silanizadas por técnica modificada, com menor consumo de acetona. Material e método: O TMA foi construído com blocos de tecido hepático, em dispositivo de base fixa, colocando-se 32 cilindros de $2 \mathrm{~mm}$ de diâmetro em duplicata e espaçamento de 2,2 mm. Quinze secções de $4 \mu \mathrm{m}$ foram colocadas em lâminas silanizadas a 4\% por técnica convencional (grupo 1), 15 em lâminas silanizadas com técnica modificada (6\% de silano e com uso mínimo de acetona) (grupo 2) e 15 em lâminas com fita adesiva comercial de acordo com as recomendações do fabricante (grupo 3). Todas as lâminas foram processadas por imuno-histoquímica para citoqueratina 18, com recuperação antigênica em tampão citrato $\mathrm{pH}$ 6, em microondas. As perdas de amostras foram quantificadas e expressas como: perda total ( $\geq 80 \%$ ), quase total ( $75 \%$ a $79 \%$ ) ou parcial ( $50 \%$ a $74 \%)$. Resultados: A perda de tecidos foi semelhante nos três grupos: com silanização tradicional, modificada ou fita adesiva comercial $(4,9$ vs. 3,1 vs. 8,1, respectivamente) (análise de variância [ANOVA], $p=0,3654)$. Uma das lâminas com a fita adesiva apresentou descolamento artefatual de todos os tecidos e outra de 20 tecidos em um dos lados. Nenhuma das lâminas silanizadas apresentou tal artefato. Conclusão: Lâminas silanizadas têm resultados satisfatórios, requerem menos treinamento técnico e reduzem os custos da utilização do TMA, justificando seu uso em pesquisa. Mais ainda, o uso da técnica modificada de silanização, com redução do volume de acetona, barateia o processo e diminui a produção de resíduos químicos.

\begin{abstract}
Introduction/objective: The tissue microarray (TMA) technique allows the evaluation of multiple tissue samples in a single block. One of the problems of TMA is the ungluing of tissue sections, thus commercial adhesive tape has been used to reduce this loss. There are no reports comparing the use of the commercial adhesive tape with the use of the modified silane-coated technique. The objective of this study was to compare section loss in slides using commercial adhesive tape, silane-coated microslides with the conventional technique or with the modified technique. Material and method: The TMA was constructed with hepatic tissue blocks embedded in paraffin, using a fixed base device, placing 32 cylinders of $2 \mathrm{~mm}$ in diameter in duplicate and $2.2 \mathrm{~mm}$ apart from each other. Fifteen 4- $\mu$ m sections were placed on conventional silane-coated microslides at 4\% (Group 1), 15 on silane-coated microslides with a modified technique (6\% of silane and minimum use of acetone) (Group 2), and 15 on slides using commercial adhesive tape, according to the manufacturer's recommendations (Group 3). All microslides were processed by immunohistochemistry for cytokeratin 18, with antigen retrieval accomplished by incubation with citrate buffer $\mathrm{pH} 6.0$ with microwave enhancement. Samples loss was quantified and expressed as: total ( $\geq 80 \%)$, almost complete (75\% to $79 \%$ ) or partial (50\% to $74 \%)$. Results: The loss of sections was similar in all three groups (4.9 vs. 3.1 vs. 8.1, respectively) (analysis of variance [ANOVA], $p=0.3654$ ). One slide using commercial adhesive tape showed artifactual ungluing of all sections and another one showed loss of 20 samples on one side of the slide. None of the silane-coated microslides showed such artifact. Conclusions: Silane-coated microslides show adequate results, require less technical training and reduce the cost of TMA procedure, what justifies their use in research. Moreover, the use of the modified silane-coating technique, with the reduction of acetone volume, lowers the costs and reduces chemical residues.
\end{abstract}

\section{key words}

TMA

Sample loss

Immunohistochemistry

Silane-coated microslides

1. Histotecnólogo do Departamento de Patologia da Escola Paulista de Medicina da Universidade Federal de São Paulo (EPM/UNIFESP); presidente da regional Sudeste da Sociedade Brasileira de Histotecnologia (SBH).

2. Médicos patologistas doutorandos do Departamento de Patologia da EPM/UNIFESP.

3. Médico residente do Departamento de Patologia da EPM/UNIFESP.

4. Bióloga pesquisadora do Departamento de Patologia da EPM/UNIFESP.

5. Mestrando do Departamento de Patologia da EPM/UNIFESP.

6. Professor titular e chefe do Departamento de Patologia da EPM/UNIFESP.

Trabalho realizado no Departamento de Patologia da EPM/UNIFESP.

Apoio financeiro da Fundação de Amparo à Pesquisa do Estado de São Paulo (FAPESP).

Trabalho apresentado e premiado como melhor pôster no XV Congresso Brasileiro de Histotecnologia, em Bento Conçalves, de 14 a 17 de novembro de 2007. 


\section{Introdução}

Em agosto de 1986, Batiffora propôs um novo método de microarranjo de tecido (multitumor tissue block [MTTB]) ou técnica de "salsicha"(2). Ele desemblocava os fragmentos incluídos em parafina, cortava-os em cilindros com $1 \mathrm{~mm}^{2}$ de área e 2 a $3 \mathrm{~cm}$ de comprimento e os reincluía paralelamente, formando blocos multiteciduais nos quais diferentes tecidos eram amostrados em pequenos quadrados justapostos. Isso permitia testar até cem amostras diferentes com apenas uma pequena alíquota de anticorpo primário, resultando em economia de reagentes e tempo de leitura, além de homogeneizar as reações. $\mathrm{O}$ autor também relatou a montagem de MTTB com arranjos temáticos, que poderiam ser usados para controle de qualidade em imuno-histoquímica. Uma limitação desse método era a não-identificação de cada amostra com o paciente correspondente. Outros autores aprimoraram a técnica ${ }^{(3,17)} \mathrm{e}$ somente em 1998 Kononen et al. ${ }^{\left({ }^{8}\right)}$ desenvolveram a base do método utilizado atualmente com o uso de dispositivo mecânico de base fixa, que consiste em dispositivo cilíndrico semelhante a punch de biópsia cutânea, em base fixa, com mecanismo para retirada do cilindro e montagem em bloco pré-moldado e vazado, com os loci para receber os cilindros. Esse dispositivo facilitou a montagem técnica dos blocos de microarranjos teciduais, ou tissue microarray (TMA), permitindo a coloração de até 600 amostras no mesmo bloco e na mesma lâmina. Os autores propuseram o corte do maior número possível de lâminas para evitar o desgaste excessivo do bloco a cada série de corte, e também que o estoque das lâminas com os cortes de TMA fosse parcialmente recoberto por parafina. Usaram fitas adesivas para a retirada dos cortes do micrótomo e a transferência dos mesmos para as lâminas, evitando perda de amostras. Posteriormente, outros autores sugeriram mudanças na confecção(15) e na análise das lâminas ${ }^{(9)}$.

Atualmente, há crescente número de publicações que buscam diminuir os custos de pesquisa envolvendo o TMA, principalmente pela adoção de métodos alternativos de confecção dos blocos ${ }^{(10,14,16,18)}$.

Um dos problemas relacionados com a técnica de TMA é o descolamento dos cortes das lâminas. Apesar de apenas alguns trabalhos reportarem a possibilidade do não-uso de fitas adesivas comerciais, os pioneiros da técnica a utilizaram, argumentando que têm menor perda de

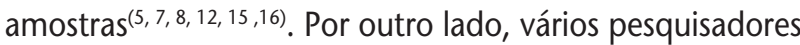
referiram bons resultados sem o seu uso, gerando redução nos custos ${ }^{(6,11)}$. Outros trabalhos chamam a atenção para um pior desempenho das fitas também nas técnicas de hibridização in situ por fluorescência (FISH) e hibridização in situ colorimétrica $(\mathrm{CISH})$, podendo inclusive causar artefatos na técnica imuno-histoquímica ${ }^{(1,13)}$.

\section{Objetivo}

O objetivo deste trabalho foi comparar o percentual de perda de amostras de tecido em lâminas especiais com o uso de fita adesiva comercial, lâminas silanizadas com técnica convencional ou com técnica modificada em blocos de TMA.

\section{Material e método}

\section{Material}

Foram selecionados, aleatoriamente, do arquivo de blocos do Departamento de Patologia da Universidade Federal de São Paulo (UNIFESP), oito blocos de parafina contendo amostras de tecido hepático. A orientação espacial das amostras na construção do TMA foi feita com diferenças na disposição dos cilindros no bloco.

\section{Construção do TMA}

A construção do bloco de TMA seguiu a técnica preconizada por Kononen et al.(8), utilizando-se o dispositivo de base fixa, com o uso de agulhas de $2 \mathrm{~mm}$ de diâmetro. Foi confeccionado bloco com 32 cilindros em espelho, sendo que de cada bloco doador foram retirados quatro cilindros aleatoriamente, totalizando 64 cilindros no bloco, com espaçamentos de 2,2 mm entre os centros dos cilindros.

\section{Técnicas de silanização das lâminas}

No grupo 1 (com silanização tradicional: TMA G1), as lâminas foram deixadas em solução detergente neutra por 2 horas e, após lavagem em água corrente até ser retirado o excesso do detergente, foram imersas seqüencialmente em três cubas contendo acetona, com imersão subseqüente em cuba contendo silano a $4 \%$ em acetona. A seguir passaram por mais três cubas de acetona e foram deixadas a secar em estufa a $58^{\circ} \mathrm{C}$. 
No segundo grupo (silanização modificada: TMA G2), as lâminas foram deixadas em solução de água destilada com detergente neutro a $10 \%$ por 2 horas, lavadas em água corrente até ser retirado o excesso do detergente e imersas seqüencialmente em três cubas contendo etanol absoluto. Na quarta cuba, a solução continha silano a $6 \%$ (diluído em acetona). Em seguida, foram imersas em mais três cubas contendo etanol absoluto, secas em estufa a $58^{\circ} \mathrm{C}$ e guardadas em temperatura ambiente.

As lâminas do terceiro grupo 3 (lâminas com fita adesiva comercial: TMA G3), denominadas especiais, foram aquelas em que se usaram fitas adesivas (Instrumedics Inc, Hackensak, NJ, EUA) e foram submetidas aos solventes e banhos de luz ultravioleta, conforme especificações do fabricante.

\section{Confecção das lâminas de TMA}

Após a confecção do bloco, este foi seccionado com $4 \mu \mathrm{m}$ de espessura em micrótomo e os cortes, aderidos em lâminas silanizadas (pelo método convencional ou modificado) ou especiais.

Para a confecção das lâminas TMA G1, os primeiros 15 cortes foram aderidos consecutivamente em 15 lâminas silanizadas convencionais numeradas de 1 a 15. Para o TMA $\mathrm{G} 2,15$ cortes seguintes foram aderidos da mesma maneira em lâminas silanizadas com a técnica modificada. Para a preparação do TMA G3 foram utilizadas lâminas especiais e fitas adesivas para a fixação dos cortes na lâmina. Nesse terceiro grupo foram também utilizados os últimos 15 cortes consecutivos. Um par de lâminas de cada grupo (lâminas 1 e 15 da seqüência de corte) foi corado por hematoxilinaeosina (H\&E) e as demais foram submetidas à técnica de imuno-histoquímica.

\section{Imuno-histoquímica}

As lâminas dos três grupos foram levadas à estufa a $57^{\circ} \mathrm{C}$ por 12 horas. A seguir foram colocadas em imersão em três banhos de xileno, sendo o primeiro por 30 min e o segundo e o terceiro por 5 min cada, seguidos por mais três banhos de 5 min em etanol absoluto e lavadas em água corrente por mais 5 min.

A recuperação antigênica foi realizada em tampão citrato, pH 6, em forno de microondas por 30 min, na potência máxima. As lâminas foram resfriadas, ainda no tampão, e lavadas em água corrente por 5 min.
O bloqueio da peroxidase endógena foi realizado com quatro banhos de 5 min cada em peróxido de hidrogênio a $20 \%(\mathrm{v} / \mathrm{v})$. A seguir foram novamente lavadas em água corrente por 5 min, em solução tampão salina de fosfato (PBS), $\mathrm{pH} 7,4$, e incubadas com anticorpo primário de camundongo anticitoqueratina 18 (clone DC 10, Cell Signalling Technology, Danvers, MA, EUA), diluído 1:100 em albumina sérica bovina (BSA) a 1\%, por 18 horas. Após lavagem em PBS, as lâminas foram incubadas com o anticorpo secundário biotinilado (kit LSAB - DakoCytomation) por 30 min, lavadas em PBS e incubadas com o segundo reagente do mesmo kit por mais $30 \mathrm{~min}$. Depois disso foram lavadas em água corrente e reveladas com DAB líquido (DakoCytomation). Os cortes foram contracorados em hematoxilina, lavados em água corrente, desidratados em etanol absoluto, diafanizados em xileno e montados com lamínula e resina (Figura 1).

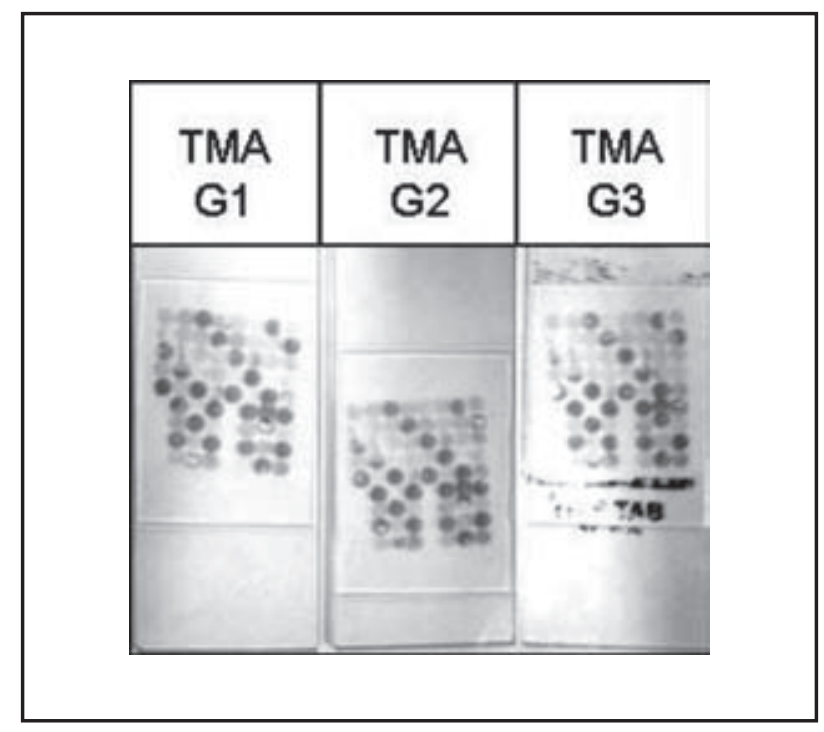

Figura 1 - Lâminas do grupo 1 (com silanização tradicional: TMA G1), grupo 2 (silanização modificada: TMA G2) e grupo 3 (lâminas com fita adesiva comercial: TMA G3)

\section{Avaliação das perdas teciduais}

A reação imuno-histoquímica para citoqueratina 18 foi realizada apenas para avaliação da perda ou descolamento do tecido após a recuperação antigênica. A avaliação das perdas foi feita por dois patologistas, tanto num espelho como no outro. Os resultados foram postos em tabelas para posterior obtenção das médias das perdas. A comparação foi realizada em todos os níveis de corte.

A Figura 2 mostra a padronização da leitura das perdas, considerando-se: 


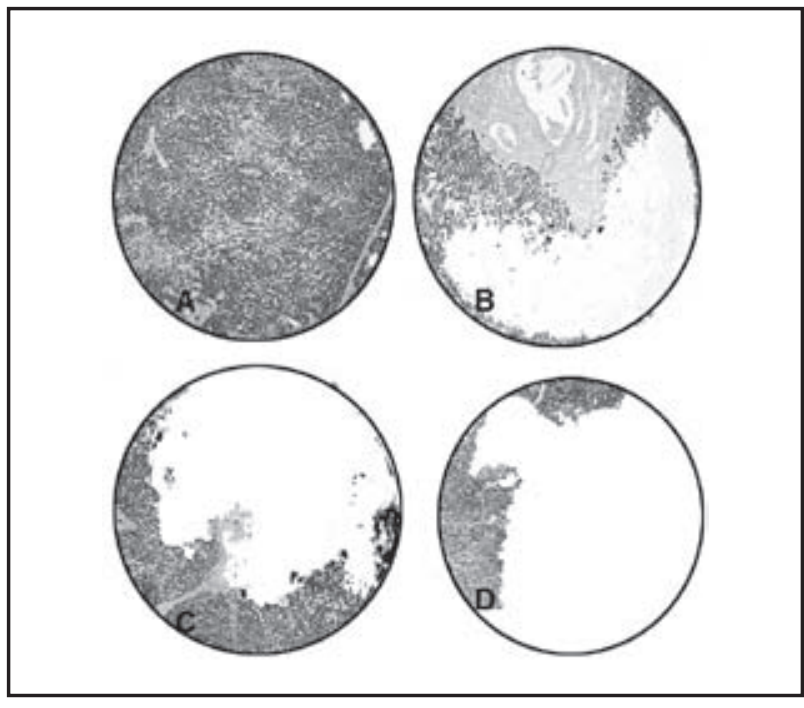

Figura 2 - Padronização da avaliação das perdas teciduais: "sem perda" (A), "perda parcial" (B), "perda quase total" (C) e "perda total" (D)

- sem perda: acima de 50\% da área do cilindro presente na lâmina

- perdas parciais: entre $50 \%$ e $74 \%$ do cilindro

- perda quase total: aquelas com ausência entre $75 \%$ e $79 \%$ da área do cilindro

- perda total: ausência de $80 \%$ ou mais da área de cada amostra.

\section{Análise estatística}

Os dados foram tabulados e submetidos à análise de variância (ANOVA), seguida do pós-teste de Bonferroni, utilizando-se o software Prism 4.0 (GraphPad Inc, San Diego, EUA).

\section{Resultados}

A Figura 3 mostra a distribuição do número de perdas de tecido e a Tabela, a média e o desvio padrão (DP) das perdas. Essa distribuição foi semelhante (ANOVA, $p=0,3654$ ) dentro do mesmo grupo de lâminas: TMA G1 (média $=4,9$ amostras), TMA G2 (média $=3,1$ amostras) e TMA G3 (média = 8,1 amostras). Uma das lâminas com fita adesiva comercial apresentou descolamento de todas as amostras (Figura 4) e uma outra, descolamento de 20 amostras em um dos lados da lâmina. Em nenhuma das lâminas silanizadas observou-se tal artefato, exceto pequenos descolamentos centrais em algumas (Figura 5).

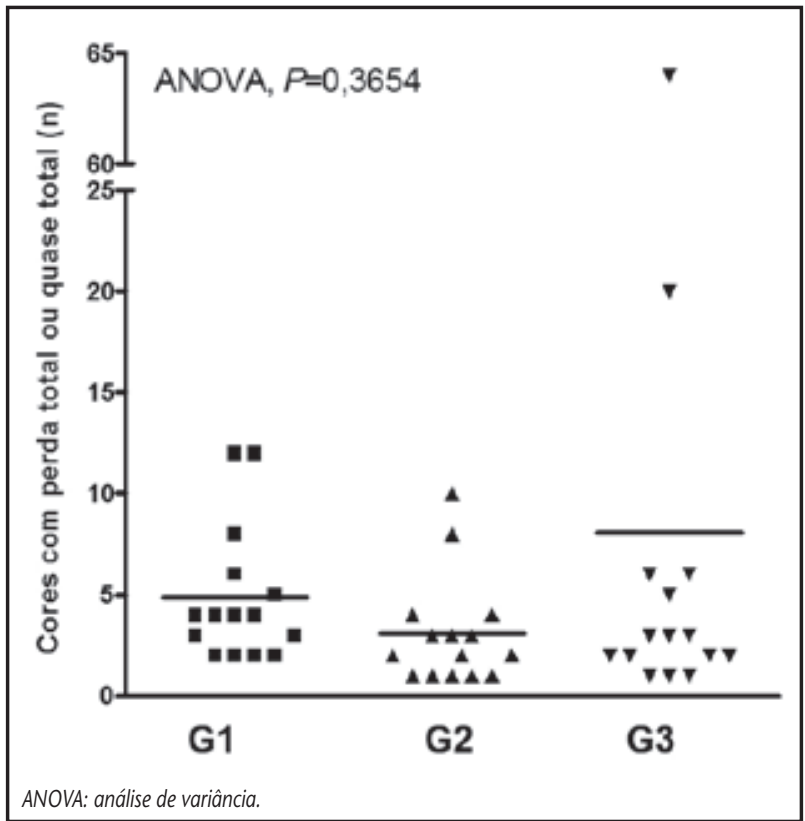

Figura 3 - Número de perdas de tecidos nos TMA G1, TMA G2 e TMA G3. A perda foi semelhante dentro de cada grupo analisado (ANOVA, $\mathrm{p}=0,3654$ )

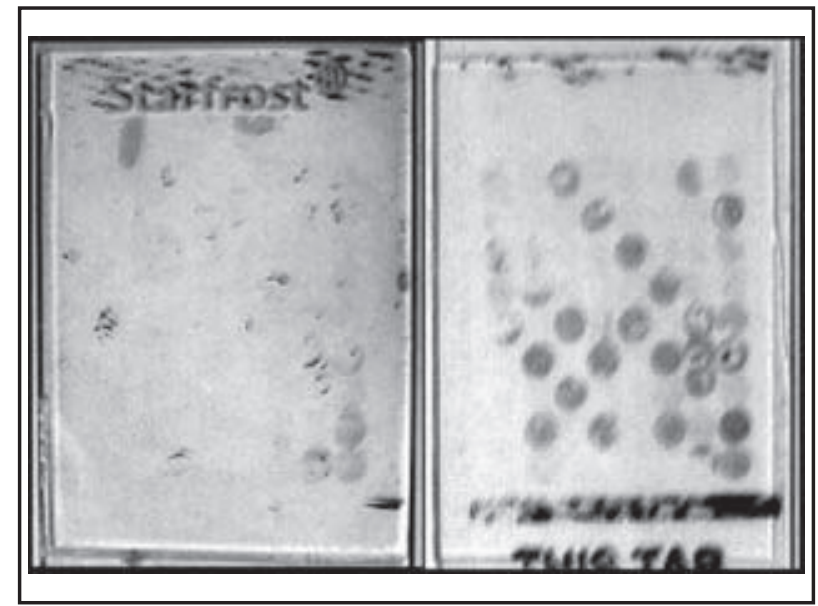

Figura 4 - Descolamentos total e parcial das amostras observados nas lâminas com uso da fita adesiva comercial

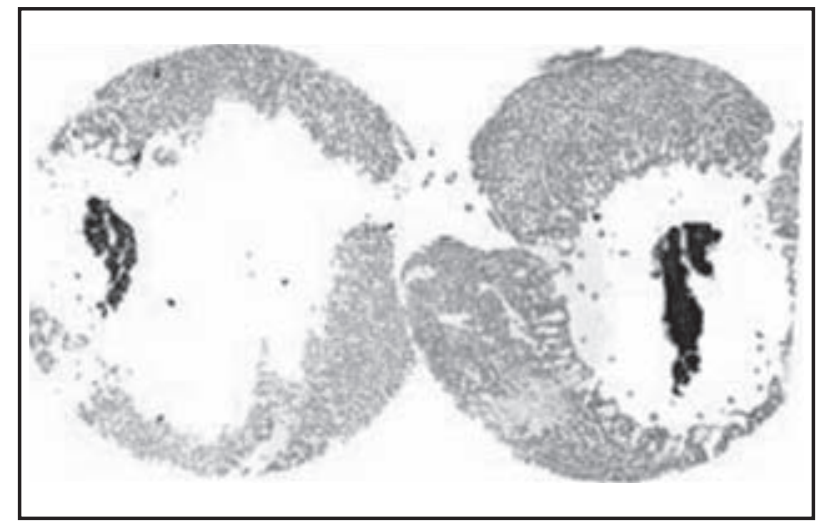

Figura 5 - Descolamentos centrais dos tecidos observados em algumas lâminas silanizadas 
Média e desvio padrão das perdas de tecidos em TMA G1, TMA G2 e TMA G3. A perda foi semelhante dentro de cada

Tabela 1 grupo analisado (ANOVA, $p=0,3654$ )

\section{Técnica adesiva}

\begin{tabular}{ccccc}
\cline { 3 - 5 } & TMA G1 & TMA G2 & TMA G3 & $p$ \\
Média & 4,9 & 3,1 & 8,1 & 0,3654 \\
\cline { 1 - 4 } Desvio padrão & 3,3 & 2,7 & 16,2 &
\end{tabular}

TMA G1: microarranjos teciduais, grupos 1, 2 e 3; ANOVA: análise de variância.

\section{Discussão}

A técnica de TMA foi descrita, em 1998, por Kononen et al.(8), com ampla aceitação mundial. Trata-se da construção de um bloco de parafina contendo fragmentos cilíndricos de amostras de tecidos obtidos de dezenas ou centenas de blocos de parafinas originais que são dispostos no bloco receptor seguindo uma ordem predeterminada ${ }^{(1)}$.

O TMA permite analisar, de uma só vez, centenas de amostras de tecidos, tanto em sua expressão molecular como protéica, e é mais comumente utilizado na pesquisa de novos marcadores prognósticos. Nos últimos cinco anos tem aumentado significantemente o número de artigos científicos que relatam a utilização dessa técnica.

Segundo a literatura, esse método tem muitas vantagens, como grande economia de tempo, reagentes, tecidos histológicos e anticorpos; uniformização das reações e facilidade na interpretação comparativa dos casos de uma pesquisa; possibilidade de repetição das reações, inclusive em múltiplos níveis de um mesmo bloco; e simplificação na execução de estudos pela utilização do bloco em mais de um experimento ${ }^{(1,17)}$. No entanto, a utilização do TMA implica também algumas desvantagens em relação à técnica convencional (blocos individuais), como limitação na representação histológica, devido à pequena amostra estudada, e perda de tecidos no procedimento imuno-histoquímico.

O uso de dispositivos de base fixa (do tipo Beecher) tornou-se o padrão-ouro para a confecção de blocos de TMA nos diversos serviços de pesquisa e diagnóstico ao redor do mundo. Tem, porém, como fatores limitantes o alto custo de implantação e a manutenção. No intuito de baixar ou eliminar esses custos, vários autores têm buscado técnicas alternativas de construção de blocos de $\operatorname{TMA}^{(1,4,10,14,18)}$.

Além disso, outro problema é a perda por descolamento das amostras de tecido dos cilindros durante a confecção dos cortes histológicos ou durante o processamento histológico ou imuno-histoquímico. A fim de contornar esse problema, foi introduzida a fita adesiva.

Atualmente, o uso da fita adesiva em associação ao uso de lâminas especialmente preparadas, soluções solventes e lâmpadas ultravioletas está amplamente difundido $(5,7,8,12,15)$. Apesar disso, essa solução traz consigo maior dificuldade técnica no ato do corte desses blocos de TMA, demandando treinamento complementar, com aumento de custos de manutenção e consumo de insumos, além de relatos de artefatos em FISH, CISH e mesmo na imuno-histoquímica ${ }^{(1,13)}$. Recentemente foram relatados bons resultados sem o uso da fita ${ }^{(6,11)}$.

Nesse estudo comparamos a confecção das lâminas de TMA utilizando a técnica do uso de lâminas especiais e da fita adesiva comercialmente disponível, lâminas silanizadas por técnica tradicional ou convencional e lâminas silanizadas por técnica modificada.

Observamos, em uma das lâminas, o descolamento de todas as amostras com o uso da fita adesiva comercial e em outra, descolamento de 20 amostras em um dos lados. Nenhuma das lâminas silanizadas de modo tradicional ou modificado apresentou tal artefato.

Como essas três técnicas são mutuamente exclusivas, exigindo seqüências diferentes no momento do corte, foi necessária a realização de quinze cortes consecutivos por três vezes.

Os cortes sem o uso da fita adesiva demandam resfriamento dos blocos com o contato direto destes com cubos de gelo. Esse procedimento confere umidade ao bloco de parafina, impedindo a adesão das fitas comerciais. Assim, as fitas adesivas não podem ser usadas em bloco resfriado, impedindo o uso de cortes intercalados para as três técnicas aqui testadas, como inicialmente planejado.

Para evitar que os níveis seqüenciais de cortes produzissem perdas de amostras por desbaste inadequado no início do corte do bloco ou por término do cilindro tecidual nos últimos cortes, as seguintes precauções foram tomadas: a) início do uso dos cortes do bloco de TMA apenas após o desbaste apropriado, conferindo a presença das amostras após coloração por HE; b) uso de 15 lâminas para cada grupo, totalizando as 45 lâminas utilizadas no estudo, uma vez que os blocos de TMA permitem o corte de até 80 lâminas antes do término dos cilindros teciduais; c) utilização de blocos doadores espessos e cortados previamente apenas uma vez; d) obtenção, no final, de corte extra, corado por $\mathrm{HE}$, para avaliar a presença das amostras. Foram utilizados 
blocos doadores de tecido hepático confeccionados em datas próximas, minimizando a variação de tempo de fixação e armazenamento.

A não-adesividade da amostra de tecido à lâmina deve ser o motivo das perdas. Não descartamos, porém, a possibilidade de a perda ter ocorrido durante o descolamento da fita adesiva por temperatura não-adequada e/ou descolamento brusco da fita.

A posição espacial de cada amostra na lâmina pode causar variação de perda da amostra. Como não analisamos a perda por posição da amostra, mas sim a perda total com cada técnica de aderência, uma eventual diferença de perda secundária à posição da amostra não causou viés na avaliação.

Algumas lâminas silanizadas apresentaram pequenos descolamentos centrais. Durante a realização da reação imuno-histoquímica, os cortes histológicos são submetidos a sucessivas variações físico-químicas, como: vários merguIhos em xilol, álcool, peróxido de hidrogênio, água, solução tampão, além de recuperação antigênica em forno de microondas e incubação por 16 a 18 horas em temperatura baixa $\left(4^{\circ} \mathrm{C}\right)$. Esses fatores técnicos podem ter sido a causa dos descolamentos centrais nas lâminas silanizadas.

O uso de fitas adesivas, com seus solventes, lâmpada e lâmina com resina própria, requer treinamento técnico específico, que se soma ao já requerido para a construção dos blocos de TMA. Devido a esse fato, realizamos nossos experimentos somente após a completa familiarização com o uso das fitas adesivas. O corte dos blocos de TMA, sem o uso das fitas, não apresentou tal problema, uma vez que já tínhamos experiência com a técnica, que se assemelha à rotina da histotecnologia.
Outra questão abordada foi o fato de que o uso da acetona, em seis banhos para a silanização das lâminas pela técnica convencional, gera problemas de ordem ecológica, com a necessidade de descarte de material poluente, além da questão de saúde ocupacional da equipe técnica, exposta a risco de natureza química. A técnica de silanização modificada, que utiliza acetona apenas na solução de silanização, dispensando seu uso nos banhos anteriores e posteriores, feitos com álcool absoluto, minimizou essas duas questões, com diminuição conseqüente de custos.

Milanes-Yearsley et al., em $2002^{(11)}$, relataram artefatos de coloração e fundo nas reações imuno-histoquímicas com o uso da fitas adesivas, fato não observado com a utilização de lâminas silanizadas.

Por fim, como perspectiva, pretendemos realizar experimentos adicionais utilizando agulhas de 0,6 e de $1 \mathrm{~mm}$ para confirmação dos dados do presente estudo.

\section{Conclusão}

Este estudo permite afirmar que as perdas de amostras com lâminas silanizadas, na técnica de TMA, é semelhante às observadas com o uso de fitas adesivas. Outra vantagem do uso de lâminas silanizadas é ser técnica de uso rotineiro em laboratórios de patologia, resultando em redução de custos, sem perda da qualidade da informação. Por fim, a técnica alternativa de silanização, com redução do volume de acetona, barateia o processo e reduz o lançamento de resíduos químicos no ambiente.

\section{Referências}

1. ANDRADE, V. P. et al. O arranjo em matriz de amostras teciduais (tissue microarray): larga escala e baixo custo ao alcance do patologista. J Bras Patol Med Lab, v. 43, n. 1, p. 55-60, 2007.

2. BATTIFORA, H. The multitumor (sausage) tissue block: novel method for immunohistochemical antibody testing. Lab Invest, v. 55, n. 2, p. 244-8, 1986.
3. BATTIFORA, H.; MEHTA, P. The checkerboard tissue block. An improved multitissue control block. Lab Invest, v. 63, n. 5, p. 722-4, 1990.

4. CHEN, N.; ZHOU, Q. Constructing tissue microarrays without prefabricating recipient blocks: a novel approach. Am J Clin Pathol, v. 124, n. 1, p. 103-7, 2005. 
5. HENSHALL, S. Tissue microarrays. J Mammary Gland Biol Neoplasia, v. 83, n. 3, p. 347-58, 2003.

6. HOOS, A. et al. Clinical significance of molecular expression profiles of Hurthle cell tumors of the thyroid gland analyzed via tissue microarrays. Am J Pathol, v. 160, n. 1, p. 175-83, 2002.

7. KALLIONIEMI et al. Tissue microarray technology for high-throughput molecular profiling of cancer. Hum Mol Genet, v. 10, n. 7, p. 657-62, 2001.

8. KONONEN et al. Tissue microarrays for high-throughput molecular profiling of tumor specimens. Nat Med, v. 4, n. 7, p. 844-7, 1998.

9. LIU, C. L. et al. TMA-combiner, a simple software tool to permit analysis of replicate cores on tissue microarrays. Mod Pathol, v. 18, n. 12, p. 1641-8, 2005.

10. MENG, P. Q. et al. Application of new tissue microarrayerZM-1 without recipient paraffin block. J Zhejiang Univ Sci B, vol. 6, n. 9, p. 853-8, 2005.

11. MILANES-YEARSLEY et al. Tissue microarray: a cost and time-effective method for correlative studies by regional and national cancer study groups. Mod Pathol, v. 15, n. 12, p. 1366-73, 2002
12. $\mathrm{MOCH}, \mathrm{H}$. et al. Tissue microarrays: what will they bring to molecular and anatomic pathology? Adv Anat Pathol, v. 8, n. 1, p. 14-20, 2001.

13. PACKEISEN et al. Demystified tissue microarray technology. Mol Pathol, v. 56, n.4, p. 198-204, 2003.

14. PIRES, A. R. et al. TMA for all: a new method for the construction of tissue microarrays without recipient paraffin block using custom-built needles. Diagn Pathol, v. 1, n. 1, p. 14, 2006.

15. RIMM, D. L. et al. Tissue microarray: a new technology for amplification of tissue resources. Cancer J, v. 7, n. 1, p. 24-31, 2001.

16. ROCHA, R. M. et al. Construção de arrays de tecido com equipamento alternativo e de baixo custo para estudo imuno-histoquímico de tumores mamários. J Bras Patol Med Lab, v. 42, n. 6, p. 477-82, 2006.

17. WAN, W. H. et al. A rapid and efficient method for testing immunohistochemical reactivity of monoclonal antibodies against multiple tissue samples simultaneously. J Immunol Methods, v. 103, n. 1, p. 121-9, 1987.

18. YAN, P. et al. An agarose matrix facilitates sectioning of tissue microarray blocks. J_Histochem Cytochem, v. 55, n. 1, p. 21-4, 2007. 